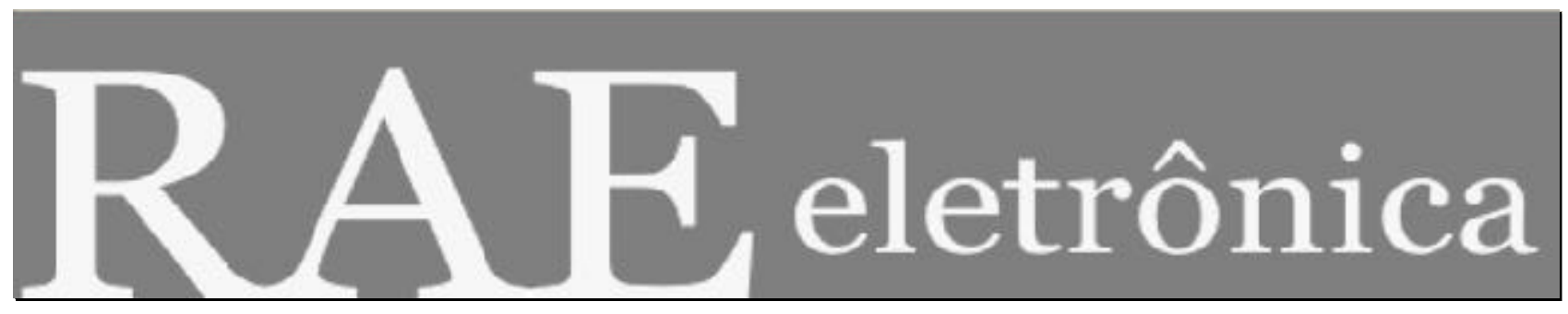

\title{
UMA AVALIAÇÃO DOS BALANÇOS SOCIAIS DAS 500 MAIORES
}

Por:

\section{José Antônio Puppim de Oliveira}

RAE-eletrônica, v. 4, n. 1, Art. 2, jan./jul. 2005

http://www.rae.com.br/eletronica/index.cfm?FuseAction=Artigo \&ID=2081\&Secao=ARTIGOS\&Volu $\mathrm{me}=4 \&$ Numero $=1 \& \mathrm{Ano}=2005$

CCopyright, 2005, RAE-eletrônica. Todos os direitos, inclusive de tradução, são reservados. É permitido citar parte de artigos sem autorização prévia desde que seja identificada a fonte. A reprodução total de artigos é proibida. Os artigos só devem ser usados para uso pessoal e nãocomercial. Em caso de dúvidas, consulte a redação: raeredacao@fgvsp.br.

A RAE-eletrônica é a revista on-line da FGV-EAESP, totalmente aberta e criada com o objetivo de agilizar a veiculação de trabalhos inéditos. Lançada em janeiro de 2002, com perfil acadêmico, é dedicada a professores, pesquisadores e estudantes. Para mais informações consulte o site www.rae.com.br/eletronica.

\section{RAE-eletrônica}

ISSN 1676-5648

(C)2005 Fundação Getulio Vargas - Escola de Administração

de Empresas de São Paulo.

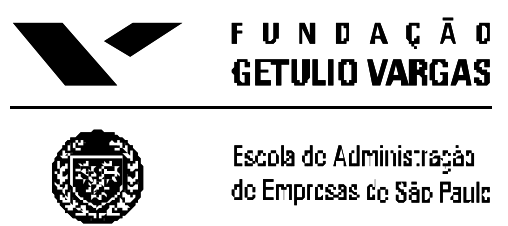




\title{
RESUMO
}

O objetivo deste artigo é analisar como as 500 maiores empresas S.A. não-financeiras do Brasil estão divulgando informações de caráter sócio-ambiental de forma organizada. O estudo coletou os balanços sociais publicados pelas empresas deste grupo, olhando de que forma publicam estes balanços e quanto de recursos disponibilizam para determinados setores sócio-ambientais. A pesquisa foi feita em face da literatura acadêmica sobre o tema e de outros estudos feitos no Brasil e no mundo. Os seguintes dados foram agregados: contribuições totais à sociedade incluindo impostos e encargos sociais, investimentos em projetos sociais externos, investimentos em meio ambiente e participação dos empregados nos resultados da empresa. Os resultados mostram que quanto maior a empresa mais se publica balanços sociais. Vê-se também que as maiores empresas brasileiras divulgam balanços sociais em número similar às maiores empresas internacionais. As empresas que mais publicam estão nos setores de atividades com alguns dos maiores impactos sociais e ambientais, como petróleo, e eletricidade e gás. Em termos de conteúdo, verificourse que falta consistência na definição de alguns termos e qualidade de algumas informações. Conclui-se que os balanços sociais devem passar por um processo de normatização voluntária para que não percam legitimidade.

\section{PALAVRAS-CHAVE}

Balanço social, responsabilidade social corporativa, transparência, gestão social, gestão ambiental.

\begin{abstract}
The objective of this article is to analyze how the 500 largest non-financial companies in Brazil are reporting on their social and environmental performance. The study collected the social reports of all companies among those companies that publish social and environmental data in an organized form, looking at the format of the publication and the amount of resources allocated to certain activities. The research was done in face of the academic literature and other studies in Brazil and abroad. The following data were aggregated: total amount of resources to society, including taxes and social security; total investments in external social projects, investments in environmental management and participation of the employees on the results. The results show that large Brazilian companies publish more data than smaller companies, and in a percentage similar to the largest World companies. Oil, and electricity and gas industry publish more social reports than others. In terms of contents, the research pointed that there is a lack of consistency in term definition and the reliability of certain information.
\end{abstract}

\section{KEYWORDS}

Social report, corporate social responsibility, transparency, social management, environmental management. 


\section{INTRODUÇÃO}

Responsabilidade Social ou Sócio-ambiental de Empresas (RSE) é um tema recente, mas de crescente interesse na mídia, empresariado, academia, governo, e sociedade civil no Brasil. Não há um uma lista rígida de coisas que uma empresa deve fazer para ser socialmente responsável. Porém, apesar de não existir uma definição consensual, responsabilidade social envolve uma gestão empresarial mais transparente e ética e a inserção de preocupações sociais e ambientais nas decisões e resultados das empresas. RSE diz respeito à maneira como as empresas agem, como impactam e como se relacionam com o meio ambiente e suas partes legitimamente interessadas (os chamados "stakeholders"). Tudo isto reflete governança corporativa, ou seja, como uma organização é governada, e conseqüentemente afeta seus resultados econômico-financeiros.

Muitas empresas estão cada vez mais se empenhando em ações na área sócio-ambiental dentro e fora de suas instalações e tentando se mostrar mais transparentes e receptivas ao diálogo com a sociedade. Essas ações ligadas à RSE são resultado da percepção de fatores econômicos, sociais e políticos (RAHAMAN, LAWRENCE \& ROPER, 2004; PUPPIM DE OLIVEIRA, 2004, 2002; MARTIN, 2002; MCWILLIANS \& SIEGEL, 2000; MAIGNAN, FERREL \& HULT, 1999). Com o aumento da necessidade de serem competitivas devido à abertura do mercado nacional e oportunidades de exportação, empresas estão buscando alternativas de se diferenciar, abrir novos mercados e melhorar sua competitividade. Mais responsabilidade sócio-ambiental pode fazer esta diferenciação. Por outro lado, com a democratização, diminuição do papel do Estado, maior atuação da mídia e conscientização da sociedade civil, a pressão social e política para uma maior responsabilidade sócio-ambiental e transparência das empresas tende a aumentar. Além de um maior interesse dos acionistas em informações sócio-ambientais de suas empresas, a relação com as partes legitimamente interessadas, os chamados stakeholders, tem mudado. Ela passou a envolver uma maior transparência e a prestação de contas a diversos atores sociais que não eram tão importantes no processo decisório anteriormente. Estes atores incluem comunidades, empregados, famílias dos empregados e organizações nãogovernamentais (ONGs). Desta forma, empresas passaram a ser mais avaliadas por suas atitudes e comportamentos frente a questões sócio-ambientais.

A avaliação da responsabilidade sócio-ambiental das empresas é importante para que tomadores de decisão nas empresas e stakeholders saibam como estão as organizações de seu interesse frente aos aspectos sócio-ambientais. O Balanço Social, ou outra publicação que disponibilize informações sócioambientais de uma organização, surge como uma das principais ferramentas para sintetizar e disponibilizar as informações sobre como a empresa vem trabalhando as questões sócio-ambientais. Entretanto, RSE deve ser resultado de uma construção política e social com os diferentes stakeholders. O papel do Balanço Social surge a partir daí, ou seja, não somente informar de maneira organizada aos stakeholders o que a empresa tem feito, mas envolve a maneira como ele é construído com os diversos stakeholders, e isto inclui também a divulgação de uma avaliação franca do que não tem sido feito e da opinião dos stakeholders sobre as ações da empresa.

No Brasil, o balanço social ganhou força pela iniciativa na década de 1980 do Instituto Brasileiro de Análises Sociais e Econômicas (IBASE), na época liderado pelo sociólogo Herbert de Souza (Betinho), de criar um movimento de transparência de organizações públicas e privadas. Em 1997, Betinho lançou uma campanha estimulando a publicação dos balanços sociais propondo um modelo de balanço social 
(o chamado Modelo IBASE $^{1}$ ), e assim abriu uma discussão mais ampla com empresários mais progressistas sobre o tema (IBASE, 2003). Isto catalisou a publicação de balanços sociais por diversas empresas. O modelo foi aperfeiçoado algumas vezes e hoje serve como um referencial no Brasil e no exterior. Além disso, existem diversas organizações que incentivam e trabalham para a divulgação de informações sócio-ambientais pelas empresas, como o Instituto Ethos ETHOS, 2003), o Conselho Empresarial Brasileiro para o Desenvolvimento Sustentável (CEBDS, 2002) e a Federação Brasileira de Bancos (Febraban). Porém, como estão as empresas brasileiras em relação à divulgação destas informações? Quem e como publicam os balanços sociais?

Buscando responder estas perguntas, o objetivo deste artigo é analisar até que ponto e como as maiores empresas brasileiras estão publicando informações sócio-ambientais de forma organizada, e quais empresas publicam. Para isto, fez-se uma pesquisa com as 500 maiores empresas S.A. não-financeiras do ranking da FGV. A análise foi feita em face da literatura e de outros estudos feitos no Brasil e no mundo.

\section{REFERENCIAL TEÓRICO: DEBATES SOBRE BALANÇO SOCIAL}

Balanço Social, Relatório de Sustentabilidade Empresarial, Balanço Social Corporativo, Relatório Social e Relatório Social-Ambiental são alguns dos no mes utilizados pelas empresas, especialistas e acadêmicos para designar o material informativo sobre a situação da empresa em relação a questões sociais e ambientais (de agora em diante neste artigo iremos chamar tal publicação de balanço social ou BS). Publicações deste tipo vêm se tornando populares no Brasil e no mundo nos últimos anos, principalmente a partir da década de 1980 (ADAMS, HILL \& ROBERTS, 1998; SIQUEIRA \& VIDAL, 2002). Diferente dos relatórios anuais das empresas que visam divulgar informações principalmente aos acionistas, o conceito básico do balanço social é difundir informações que interessem a outros stakeholders além dos acionistas, como sindicatos, empregados e seus familiares, comunidades afetadas pela empresa, mídia e organizações não-governamentais (ONGs) com determinados interesses na empresa (ambientalistas, por exemplo). Para isto, o balanço social deve conter informações qualitativa e quantitativa sobre como a empresa está desempenhando sua função social e ambiental na sociedade e sua relação com os diversos stakeholders.

Existem vários motivos porque as empresas publicam balanços sociais. Alguns dos principais motivos são o atendimento às demandas dos stakeholders por informações sócio-ambientais e objetivando uma melhoria de imagem (LEWIS \& UNERMAN, 1999; ANDRADE ET AL., 2002). Por um lado, os stakeholders, além dos acionistas, estão cada vez mais buscando informações sócio-ambientais sobre empresas de seu interesse, criando uma demanda sobre elas para produzirem os balanços sociais. Por outro lado, a popularização dos balanços sociais cresce junto com o interesse das empresas, e da sociedade em geral, na questão de responsabilidade social. Os balaços sociais são uma forma de as empresas divulgarem suas versões sobre de que forma elas estão buscando uma responsabilidade social.

As informações contidas nos balanços sociais variam devido a vários fatores, como setor industrial, tamanho, tipo gerencial e contexto regional e temporal em que a empresa está inserida (ADAMS, HILL \& ROBERTS, 1998; LEWIS \& UNERMAN, 1999; TEOH \& THONG, 1984). Isto vai depender do 
interesse e capacidade de a empresa produzir os balanços sociais e do tipo de pressão dos stakeholders. Por exemplo, na década de 1970s, os balanços sociais das empresas americanas focavam mais em relação ao emprego de minorias, já que era um tema de relevância na época neste país; no Canadá havia uma ênfase em questões de benefícios trabalhistas (LEWIS \& UNERMAN, 1999). Mesmo estando dentro de um contexto de integração forte como a União Européia, os conteúdos e formas dos balanços sociais dos países europeus variam significantemente (ADAMS, HILL \& ROBERTS, 1998). Também há uma diferença entre os balanços sociais de empresas destes países e do Brasil (FREIRE \& REBOUÇAS, 2001).

Como classificar ou consolidar as informações sociais e ambientais também veio de diferentes movimentos. Até a década de 1990, percebe-se que havia vários movimentos distintos para relatar informações sócio-ambientais no Brasil e no mundo. De um lado um movimento para publicação de informações de caráter mais relacionados à ação social da empresa, como os primeiros modelos do IBASE no Brasil. Uma outra tendência priorizava os aspectos de gestão e transparência, como nas pesquisas de benchmarking do Instituto Etho s. Um terceiro movimento, ainda, direcionava mais para busca de informações ambientais, no estilo dos relatórios de sustentabilidade do Conselho Empresarial Brasileiro para o Desenvolvimento Sustentável (CEBDS). Hoje há uma tendência de integração das informações sociais e ambientais em um único documento (LINE, HAWLEY \& KRUT, 2002).

A forma de divulgação do balanço social também varia, podendo ser um documento separado ou integrado ao relatório anual da empresa. Com a expansão do uso da tecnologia de informação, a utilização da Internet para disponibilização dos balanços sociais tem crescido (LINE, HAWLEY \& KRUT, 2002).

Também tem surgido um movimento de integração global entre os diversos movimentos e organizações nacionais e regionais que lidam com a questão de responsabilidade sócio-ambiental. No âmbito do balanço social, existe uma tentativa de integração global das diversas tendências de publicações de informações sócio -ambientais através da Global Reporting Initiative - GRI (GRI, 2003). O GRI tenta difundir a importância de publicar-se balanços sociais e uma padronização mínima que os balanços devem ter para que sejam de utilidade aos diferentes stakeholders.

Sobre o ponto de vista da profundidade e tecnicidade do conteúdo e formato dos balanços existe muita divergência na literatura. Será que eles devem ser estritamente técnicos para serem analisados somente por especialistas, ou devem ser simples para que todos os stakeholders possam entendê-los? Alguns autores defendem uma forma mais simplificada de balanços, dizendo que seu principal objetivo é a divulgação de informações para um público (stakeholders) majoritariamente não familiarizado com as tecnicidades da contabilidade. Os balanços financeiros, por exemplo, não tem muita utilidade para muitos stakeholders, pois são de difícil interpretação (SUTTON \& ARNOLD, 1998). Por outro lado, há autores que defendem que balanços devem ter o rigor técnico, e que mesmo assim podem ser utilizados por vários stakeholders (SHAOUL, 1998; PRESTON, 1981).

O relativismo ético do contexto em que uma empresa está inserida é importante para pensar-se na padronização dos balanços sociais. O que é bom e o que é ruim para uma sociedade $\mathrm{A}$ hoje pode não ser para outra sociedade B ou mesmo na própria sociedade A no futuro. Assim uma padronização poderia impedir esta adaptação de acordo com as mudanças de contexto (LEWIS \& UNERMAN, 1999).

Alguns autores destacam a utilidade dos balanços sociais para catalisar mudanças nas empresas (DIERKES \& ANTAL, 1985). O impacto da publicação dos balanços sociais pode acontecer via 
stakeholders externos ou internos, incluindo a gerência. Stakeholders internos (ex: empregados) e externos podem fazer demandas às empresas baseadas nas informações publicadas pelo balanço, ou até mesmo decisões de compra no caso dos consumidores. No lado da gerência, o balanço social serve para balizar o planejamento da empresa em termos de objetivos e metas na área sócio-ambiental. O próprio processo de confecção do balanço social pode ter um impacto positivo na organização, pois esta pode descobrir aspectos que antes não conhecia (DIERKES \& ANTAL, 1985).

Há um debate também sobre a necessidade ou não de fazer os balanços sociais das empresas obrigatórios e regulados. Os defensores de uma maior regulação dos balanços sociais alegam duas razões principais (ROBERTS, 1998; SUTTON \& ARNOLD, 1998). A primeira é que stakeholders, além dos acionistas, tem pouco poder de pressão para demandar que certas informações sejam passadas de forma correta, e muitas vezes suas demandas por determinado tipo de informação são ignoradas pelas empresas ou pelas auditorias especializadas. A segunda razão é que o nível de qualidade dos balanços divulgados não é satisfatório. Em alguns países, como a França, desenvolveram formas de regular os balanços sociais (FREIRE \& REBOUÇAS, 2001). No Brasil, a publicação do balanço social não está regulamentada (SIQUEIRA \& VIDAL, 2002). Porém, alguns projetos de lei ou regulamentação que tratam do balanço social têm tramitado nas esferas federal, estadual e municipal. Em Porto Alegre, por exemplo, a publicação do balanço social já está regulamentada pela Lei 8.118 de 1998. A Agência Nacional de Eletricidade (ANEEL, 2003) tem uma resolução que torna compulsória a publicação de balanços sociais por empresas do setor elétrico já em 2003.

No Brasil, os debates da literatura podem ser melhor analisados na prática através de um estudo sobre os balanços sociais publicados por empresas instaladas no país. Neste artigo, uma reflexão sobre balanço social será feita a partir do universo de balanços publicados pelas 500 maiores empresas S.A. não-financeiras que se segue abaixo.

\section{METODOLOGIA}

Nesta pesquisa, buscoutse elaborar uma metodologia de avaliação sócio-ambiental de empresas para o universo das empresas que constam no ranking das 500 maiores empresas não-financeiras divulgadas pela Fundação Getulio Vargas em agosto de 2002 (FGV, 2002) com dados relativos a 2001. Escolhemos este universo porque já estavam disponibilizadas pela FGV várias informações em relação às empresas, como receita operacional líquida e lucro líquido. O objetivo principal é consolidar e analisar os principais dados sócio-ambientais apresentados pelas empresas e analisar de que forma são publicados.

Pensamos que a transparência das empresas é um critério importante para avaliar a responsabilidade social de uma organização. A quantidade e qualidade das informações sócio-ambientais disponíveis ao público de uma empresa balizam o comprometimento social desta empresa. Somente com informações detalhadas e confiáveis seus stakeholders podem avaliar se realmente a empresa está cumprindo suas responsabilidades frente à sociedade.

Para coleta de dados, utilizamos como fonte principal as informações publicadas pelas próprias empresas através de seus balanços sociais, seus relatórios anuais ou outros documentos disponíveis ao 
público. Estes dados foram coletados através dos sítios das empresas diretamente e por contato com as empresas via e-mail ou telefone ${ }^{2}$ entre agosto de 2002 e fevereiro de 2003. Tentamos obter as informações de todas as 500 empresas do ranking da FGV.

Uma vez tendo os balanços sociais de todas as empresas do ranking das 500 maiores da FGV, começamos a analisá-los. Dependendo da qualidade das informações disponíveis, separamos as empresas que poderiam ser avaliadas com mais profundidade para uma consolidação e comparação de suas informações sócio-ambientais. A partir daí elaboramos diversas análises contendo informações objetivas que podem ser retiradas dos dados fornecidos pelas empresas ao público, tais como:

Total de contribuições à sociedade e governo, incluindo impostos e encargos sociais (soma dos indicadores internos e indicadores externos da terminologia do IBASE [2003]. Indicadores Sociais Internos - Incluem todos os recursos gastos pela empresa em ações sociais dentro da organização, tais como encargos sociais, participação nos resultados, alimentação, previdência complementar, saúde, capacitação, creche e outros. Indicadores Sociais Externos - Incluem todos os recursos gastos pela empresa em ações fora da organização, tais como projetos comunitários, investimento em cultura, eventos esportivos e tributos).

Total de recursos investidos em ação social (projetos sociais externos),

Total de recursos investidos em ação social em proporção à Receita Operacional Líquida da empresa (ROL) (Receita Operacional Líquida (ROL) - Vendas brutas menos devoluções, descontos e impostos incidentes sobre vendas. Representa o poder de mercado da empresa. Nesta publicação utilizamos a ROL referente ao ano de 2001 do Ranking das 500 maiores empresas S.A. não financeiras da revista Conjuntura Econômica em agosto de 2002).

Participação dos empregados nos resultados das empresas em proporção à Receita Operacional Líquida (ROL), (Participação nos Resultados - Quantidade de recursos disponibilizados para participação dos empregados nos lucros ou outros resultados dentro empresa. Ele pode variar individualmente de acordo, por exemplo, com o departamento, desempenho pessoal e função da empresa. Cada organização tem seu critério de distribuição)

Total de investimentos ou indicadores de meio ambiente (Indicadores de Meio Ambiente Incluem todos os recursos gastos pela empresa em meio ambiente. Algumas empresas dividiram os investimentos entre projetos relacionados à operação da empresa e projetos externos. Outras não fizeram esta divisão. Em outros casos, as empresas colocaram os projetos ambientais externos junto com os indicadores sociais externos. Nesses casos, não modificamos a tipologia colocada pela empresa),

Total de gastos em meio ambiente em proporção à Receita Operacional Líquida (ROL).

Também fizemos um ranking destacando as empresas que mais aportaram recursos em cada um dos itens acima.

\section{RESULTADO DO PROCESSO DE COLETA DE INFORMAÇÕES}


Depois de contatar todas as 500 empresas do Ranking das S.A. não-financeiras da FGV, recebeu-se informações sobre 152 empresas, aproximadamente 30\% das 500 (Tabela 1). Participaram do estudo final 95 empresas, pois somente estas apresentavam em 2002 dados relevantes de 2001 que pudessem ser objeto de comparação com outras empresas.

Tabela 1 - Empresas que responderam entre as 500 maiores S.A. não-financeiras da FGV

\begin{tabular}{|l|l|l|}
\hline Grupo de Empresas & Balanços & \% das 500 \\
\hline $\begin{array}{l}\text { Empresas que publicaram em 2002 os balanços sociais de 2001, com } \\
\text { informações relevantes }\left(^{*}\right)\end{array}$ & 100 & $20 \%$ \\
\hline $\begin{array}{l}\text { Empresas que publicaram em 2002 algum balanço social de 2001, mas } \\
\text { com pouca informação relevante }\end{array}$ & 30 & $6,0 \%$ \\
\hline $\begin{array}{l}\text { Empresas com balanços de 2001 publicados pelo Holding } \\
\text { Empresas que em 2002 tinham balanços publicados em 2000 }\end{array}$ & $9\left(^{* *}\right)$ & $1,8 \%$ \\
\hline Empresas com balanços publicados de 2000, mas incompletos & 6 & $1,4 \%$ \\
\hline Total de empresas com balanços & 152 & $1,2 \%$ \\
\hline
\end{tabular}

(*) Consideramos informações relevantes dados qualitativos e quantitativos com alguma consolidação para que se possa fazer comparações entre empresas e ao longo dos anos. (**) em 4 balanços

Durante o processo de coleta de informações percebemos que algumas empresas não reconhecem imediatamente o significado de balanço social ou informações sócio-ambientais. Como resultado, tivemos empresas que enviaram o relatório anual ou balanço patrimonial pensando que se tratava do balanço social. Portanto, ainda é necessário um esforço maior na divulgação do conceito de balanço social e responsabilidade social.

Muitas empresas já disponibilizam informações sócio-ambientais pela internet, e assim facilitam a coleta das informações pelos stakeholders. Conseguimos 103 balanços via sítio da empresa ou enviados por email. Quarenta empresas enviaram o balanço impresso, após contato telefônico. Outro ponto interessante é que um grupo de empresas começa a colocar o balanço social como parte integrante de seu relatório anual. Trinta e seis empresas já publicam o balanço social junto com seu relatório anual, enquanto cento e dez publicam o balanço social separado. Desta forma, acionistas e outras partes interessadas têm informações do balanço social juntas com outras informações importantes relativas à empresa, facilitando o entendimento do contexto em que a empresa se encontra. Muitos dos balanços sociais apresentados no relatório anual são auditados por empresas independentes especializadas, principalmente aqueles que vem junto com o relatório anual.

O modelo proposto pelo Instituto Brasileiro de Análises Sociais e Econômicas (IBASE), instituto pioneiro no esforço de propagar a idéia de balanço social entre as empresas, começa a se popularizar entre os diversos setores empresariais. Mais de um terço dos balanços analisados, ou 34 balanços, continham informações no modelo proposto pelo IBASE (Tabela 2). Porém, a maioria das empresas ainda utiliza modelos diversos, muitos deles corporativos. 
Tabela 2 - Modelo da disponibilização das informações sócio-ambientais

\begin{tabular}{|c|c|c|c|}
\hline \multirow[t]{2}{*}{ Modelo IBASE } & \multicolumn{2}{|c|}{ Outros Modelos com Informações Relevantes } & \multirow{2}{*}{$\begin{array}{l}\text { Sem informações } \\
\text { relevantes }\end{array}$} \\
\hline & Quantitativo somente & Quantitativo e Qualitativo & \\
\hline 34 & 41 & 36 & 36 \\
\hline
\end{tabular}

Parte dos balanços foi dispensada de uma análise mais detalhada porque apresentaram pouca informação relevante, como somente descrição superficial de projetos sociais ou área de atuação social da empresa.

A publicação de balanços sociais parece ser uma prática mais comum no grupo das empresas maiores (Tabela 3 e 4). Das 10 primeiras do Ranking FGV das 500 maiores, 9 publicam balanços (90\%); das 100 primeiras, 46 publicam (46\%); enquanto a publicação acontece em somente 7 das 100 empresas classificadas entre 301 e 400 (7\%) e 9 das empresas classificadas entre 401 e 500 (9\%).

Tabela 3 - Quem Publica? Pela posição no ranking das 500 da FGV - I

\begin{tabular}{|l|l|l|}
\hline $\begin{array}{c}\text { Posição no Bloco das 500 } \\
\text { maiores }\end{array}$ & Empresas que publicaram BS & Percentual na faixa \\
\hline Entre as 500 & 105 & $21,0 \%$ \\
\hline 10 primeiras & 9 & $90,0 \%$ \\
\hline 20 primeiras & 16 & $80,0 \%$ \\
\hline 100 primeiras & 46 & $46,0 \%$ \\
\hline 250 primeiras & 78 & $31,2 \%$ \\
\hline Empresas de 251-500 & 27 & $10,8 \%$ \\
\hline
\end{tabular}

Tabela 4 - Quem Publica? Pela posição no ranking das 500 da FGV - II

\begin{tabular}{|l|l|l|}
\hline Classificação no ra nking & Empresas que publicaram BS & Percentual na faixa \\
\hline Empresas de 1-100 & 46 & $46,0 \%$ \\
Empresas de 101-200 & 25 & $25,0 \%$ \\
\hline Empresas de 201-300 & 18 & $18,0 \%$ \\
\hline Empresas de 301-400 & 7 & $7,0 \%$ \\
\hline Empresas de 401-500 & 9 & $9,0 \%$ \\
\hline
\end{tabular}

\section{DESTAQUES SETORIAIS}

Em uma divisão de balanços coletados por setores de atividade, os destaques vão para os setores onde mais de 50\% de suas empresas entre as 500 maiores publicaram balanços sociais, como os setores de aeronaves, petróleo, produtos do fumo, eletricidade e gás, e papel e celulose (Tabela 5). Alguns destes setores estão possivelmente entre os mais questionados pelos diversos atores sociais, já que englobam atividades com alto potencial de impactos ambientais e sociais. Assim, a publicação de informações sócio-ambientais é uma maneira de tentar mostrar e sensibilizar aos stakeholders como a empresa trata 
destes aspectos. Um destaque especial vai para o setor de eletricidade e gás onde 36 empresas (62\% das 58 empresas do setor) publicaram seu balanço social em 2001. Isto é devido em parte pela atuação da Aneel (Agência Nacional de Energia Elétrica), que incentiva desde 1998 as empresas do setor elétrico a publicarem seus balanços sociais. A Resolução no. 444 de 2001 coloca obrigatória a publicação em 2003 dos balanços referentes a 2002 (ANEEL, 2003).

\section{Tabela 5 - Quem publica? Por Setores}

\begin{tabular}{|l|l|l|l|}
\hline Setor de atividade & $\begin{array}{l}\text { Número de } \\
\text { empresas } \\
\text { no setor }\end{array}$ & $\begin{array}{l}\text { Com } \\
\text { Balanço }\end{array}$ & $\begin{array}{l}\text { Percentual } \\
\text { com Balanço } \\
\text { Social }\end{array}$ \\
\hline Aeronaves, Embarcações e Serviços Ferroviários & 1 & 1 & $100,0 \%$ \\
\hline Petróleo & 5 & 4 & $80,0 \%$ \\
\hline Produtos do fumo & 3 & 2 & $66,7 \%$ \\
\hline Eletricidade e Gás & 58 & 36 & $62,1 \%$ \\
\hline Celulose e Papel & 12 & 7 & $58,3 \%$ \\
\hline Couros e calçados & 3 & 1 & $33,3 \%$ \\
\hline Metalurgia & 36 & 10 & $27,8 \%$ \\
\hline Bebidas & 12 & 3 & $25,0 \%$ \\
\hline Vestuário & 4 & 1 & $25,0 \%$ \\
\hline Produtos Químicos & 46 & 10 & $21,7 \%$ \\
\hline Edição e Impressão & 5 & 1 & $20,0 \%$ \\
\hline Saneamento & 17 & 3 & $17,6 \%$ \\
\hline Comércio por atacado & 29 & 5 & $17,2 \%$ \\
\hline Artigos de Borracha e Plástico & 6 & 1 & $16,7 \%$ \\
\hline Extração Mineral & 12 & 2 & $16,7 \%$ \\
\hline Atividades anexas e auxiliares ao transporte & 7 & 1 & $14,3 \%$ \\
\hline Produtos farmacêuticos e veterinários & 7 & 1 & $14,3 \%$ \\
\hline Comércio varejista & 22 & 3 & $13,6 \%$ \\
\hline Telecomunicações & 30 & 4 & $13,3 \%$ \\
\hline Açúcar e Álcool & 9 & 1 & $11,1 \%$ \\
\hline Máquinas, aparelhos e equipamentos elétricos & 9 & 1 & $11,1 \%$ \\
\hline Material eletrônico e equipamentos de comunicação & 9 & 1 & $11,1 \%$ \\
\hline Produtos Têxteis & 10 & 1 & $10,0 \%$ \\
\hline Produtos de Minerais não- metálicos & 22 & 2 & $9,1 \%$ \\
\hline Fabricação e montagem de veículos automotores, partes e peças & 12 & 1 & $8,3 \%$ \\
\hline Construção & 20 & 1 & $5,0 \%$ \\
\hline Serviços de transporte & 20 & 1 & $5,0 \%$ \\
\hline Outros setores que nenhuma empresa respondeu 3 & 74 & 0 & $0,0 \%$ \\
\hline & 2 & \\
\hline
\end{tabular}

Por outro lado, os balanços sociais com dados relevantes inexistem em alguns setores importantes como nos setores de produtos alimentícios e máquinas e equipamentos, com 27 e 15 empresas respectivamente, onde nenhuma empresa publicou informações sócio-ambientais relevantes em 2001. Nos setores de construção e transporte, com 20 empresas cada, a publicação de balanços sociais também é bastante modesta. Somente uma empresa em cada setor publicou balanço social em 2001 . 


\section{ANÁLISE DOS DADOS DOS BALANÇOS SOCIAIS}

Dos 105 balanços selecionados inicialmente, um grupo de 95 empresas apresentaram em 2002 dados de 2001 de forma a poder colher as informações para comparações nos diversos itens que procuramos analisar objetivamente ${ }^{4}$. Dez empresas que tinham balanços sociais com informações relevantes não puderam ser comparadas com outras empresas por questões diversas, como no caso de algumas empresas que apresentavam o balanço social do holdings ou outras que publicaram seu balanço social em dólares americanos.

\section{Total de contribuições à sociedade, incluindo impostos e encargos sociais}

Este item busca determinar o valor total de contribuições das empresas para a sociedade e governo, incluindo todos os itens dos indicadores sociais internos, indicadores sociais externos e indicadores de meio ambiente como impostos, encargos sociais, participação dos empregados no resultado, ação social e investime ntos em meio ambiente.

Os balanços de 82 empresas apresentavam informações suficientes para fazer uma avaliação do valor total de suas contribuições para a sociedade em 2001. A soma da contribuição destas empresas chegou a $\mathrm{R} \$ 63,3$ bilhões. Isto gerou uma média de $\mathrm{R} \$ 772$ milhões por empresa e 32,3\% da soma da Receita Operacional Líquida dessas 82 empresas (Tabela 6).

Um destaque especial tem que ser feito à Petrobras, pelo tamanho da empresa. Somente a contribuição da gigante de petróleo, primeira no ranking de contribuições totais, foi de $\mathrm{R} \$ 30,4$ bilhões. Para se ter uma idéia, este valor era mais alto do que os ativos totais em 2001 da segunda maior empresa do ranking FGV (Telefonica).

Tabela 6 - Total de contribuições para sociedade e governo, incluindo impostos e encargos (de 82 empresas)

\begin{tabular}{|l|l|}
\hline Total de Contribuições (R\$ mil) & 63.304 .559 \\
\hline Média por empresa $(\mathrm{R} \$$ mil) & 772.007 \\
\hline Média Total de Contribuições por Receita Operacional Líquida (ROL) & $32,3 \%$ \\
\hline
\end{tabular}

Além da Petrobras, já esperada no topo do ranking por ser a maior empresa do Brasil, encabeçam a lista a Souza Cruz, pelo alto volume de impostos pagos pelo setor de produtos do fumo, Brasil Telecom e três empresas de eletricidade e gás: Cemig, Eletropaulo Metropolitana e Copel. Oito empresas das 82 analisadas tiveram uma contribuição total para a sociedade e governo de mais de $\mathrm{R} \$ 1$ bilhão cada em 2001. 
O setor de eletricidade e gás com 6 empresas e o setor de metalurgia com 5 empresas foram os que mais forneceram empresas para o ranking das 20 que mais contribuíram.

\section{Recursos Investidos em Ação Social}

Dos 95 balanços analisados, 71 empresas mostraram o total de recursos investidos em ações sociais, ou seja, projetos sociais externos à empresa, diretamente ou em parceria com outras organizações.

As 71 empresas analisadas investiram mais de $\mathrm{R} \$ 718$ milhões em ações sociais (Tabela 7). Este valor é equivalente a 0,39\% da soma de suas Receitas Operacionais Líquidas (ROL) ou 3,66\% da soma de seus lucros líquidos (LL) (sendo Lucro Líquido $(L L)$ - O resultado final da empresa, após pagamento de impostos, resultado não-operacional, participação dos empregados e outros itens. É o lucro que cabe ao acionista. Nesta publicação utilizamos o LL referente ao ano de 2001 do Ranking das 500 maiores empresas S.A. não financeiras da revista Conjuntura Econômica na edição de agosto de 2002).

Tabela 7 - Investimentos em ação social (de 71 empresas)

\begin{tabular}{l|l|}
\hline Total de Investimentos com Ação Social (R\$ mil) & 718.341 \\
\hline Média por empresa (R\$ mil) & 10.117 \\
\hline Média Total de Gastos em Ação Social por ROL & $0,39 \%$ \\
\hline Total de Gastos em Ação Social por Lucro Líquido (LL) & $3,66 \%$ \\
\hline
\end{tabular}

A Petrobras mais uma vez aparece à frente do ranking, tendo investido mais de R\$ 130 milhões em diversas ações sociais. A gigante petroleira vem seguida da Chesf, Eletronorte e Petrobras Distribuidora, cada uma investindo mais de R \$ 50 milhões em ações sociais. Quinze empresas investiram mais de $\mathrm{R} \$ 10$ milhões cada. O destaque setorial vai para o setor de eletricidade e gás, com metade das empresas (10) entre as 20 que investiram mais em ações sociais.

Quando comparamos o total investido em ações sociais com a Receita Operacional Líquida (ROL), temos um resultado diferente. No ranking das 20 empresas que mais investiram em ações sociais dividido pela ROL, somente aparecem 10, ou metade, das 20 empresas que mais investiram em ação social em valores absolutos. A Zero Hora- RBS aparece no topo do ranking investindo em ações sociais externas o equivalente a 9,39\% de sua ROL. Seguem Copel e Eletronorte com mais de 3\%. O setor de eletricidade e gás foi o que mais contribuiu outra vez, com 6 empresas nas sete primeiras e 12 entre as 20 que mais contribuíram em ação social por ROL.

\section{Participação dos empregados nos resultados das empresas em proporção à Receita Operacional Líquida (ROL)}

Das informações recebidas, constam que 58 empresas deram alguma forma de participação aos empregados nos resultados, totalizando $\mathrm{R} \$ 1,2$ bilhões em 2001 (Tabela 8). Isto é equivalente a 0,66\% da ROL e 5,93\% do Lucro Líquido (LL) do conjunto dessas empresas. Em valores absolutos totais, a Petrobras foi a que mais deu participação aos seus empregados com $\mathrm{R} \$ 416,5$ milhões em 2001. 
Tabela 8 - Participação dos empregados nos resultados (de 58 empresas)

\begin{tabular}{|l|l|}
\hline Soma total das 58 empresas (em 1.000 R\$) $=$ & 1.202 .469 \\
\hline Participação/ROL $=$ & $0,66 \%$ \\
\hline Participação/lucro líquido (LL) $=$ & $5,93 \%$ \\
\hline
\end{tabular}

Em relação às empresas que mais premiam seus funcionários com participação nos lucros ou resultados em proporção à Receita Operacional Líquida (ROL), a empresa Zero Hora-RBS está outra vez na frente do ranking com 3,42 \% da ROL, seguida da Belgo, Copel e Ultragaz, as três com mais de $2 \%$ de sua ROL dada como participação aos empregados. Os setores de metalurgia e eletricidade e gás, com 4 empresas cada, foram os que mais forneceram empresas entre as 20 primeiras que mais premiaram em relação a ROL.

\section{Investimentos em Meio Ambiente}

Um grupo de 77 empresas apresentou o balanço dos investimentos em meio ambiente. A forma de apresentar não foi homogênea. Algumas empresas dividiram os investimentos entre projetos relacionados à operação da empresa e projetos externos. Outras não fizeram esta divisão. Aqui consideramos investimentos internos e externos de forma agregada.

Os investimentos em meio ambiente em 2001 chegaram a $\mathrm{R} \$ 1,84$ bilhões de reais nessas 77 empresas, ou aproximadamente $1 \%$ da soma de suas ROLs. Em total investido por empresa, a Petrobras aparece em primeiro no ranking com $\mathrm{R} \$ 1,1$ bilhões, ou seja, quase $60 \%$ do que foi investido pelo grupo de 77 empresas pesquisadas (Tabela 9). O ranking segue com CSN, Eletronuclear, CVRD (Vale) e Celpe, cada uma investindo mais de R \$ 50 milhões cada. Mais uma vez o setor de eletricidade e gás, com 10 empresas, foi o que teve maior número de empresas entre as 20 que mais investiram em meio ambiente.

Tabela 9 - Investimentos em meio ambiente (de 77 empresas)

\begin{tabular}{|l|l|}
\hline Total gasto em meio ambiente $(1.000 \mathrm{R} \$)=$ & 1.839 .911 \\
\hline Total gasto em Meio Ambiente / ROL $=$ & $1,03 \%$ \\
\hline Média por empresa (em 1.000 R $\$)=$ & 23.895 \\
\hline
\end{tabular}

No total de investimentos em meio ambiente em relação a sua ROL, de acordo com as informações em seu balanço social, Celtins (Cia de Energia Elétrica do Estado do Tocantins) aparece em primeiro lugar com investimentos ambientais que ultrapassam os $26 \%$ de sua ROL, bem a frente de outras. Ela é acompanhada a seguir por Eletronuclear, CPTM (Cia Paulista de Trens Metropolitanos), Celpe (Cia Energética de Pernambuco) e CSN (Cia Siderúrgica Nacional). As empresas de eletricidade aparecem com destaque mais uma vez, tendo 7 entre as 20 que mais investiram em meio ambiente em relação a sua ROL. Porém, elas incluem na área ambiental os seus programas de pesquisa e desenvolvimento, eficiência energética e eletricidade rural. 


\section{CONCLUSÕES}

A publicação de balanços sociais por empresas brasileiras vem se tornando uma realidade. Sem entrar em mérito sobre a qualidade das informações, o número de empresas brasileiras que publicam balanços sociais já é relativamente alto, chegando a $46 \%$ das 100 maiores empresas S.A. não-financeiras, mesmo quando comparado internacionalmente. Um levantamento mostrou que, em 2001, 50\% das 100 maiores empresas do mundo (por lucro) publicaram balanços sociais, acima dos 44\% que publicaram em 1999 (LINE, HAWLEY \& KRUT, 2002B). Embora não tenhamos informações detalhadas sobre como vem crescendo o número de balanços sociais mas empresas brasileiras, há indícios que ele vem aumentando de forma significativa, já que muitos balanços coletados nesta pesquisa eram os primeiros a serem produzidos pelas empresas. A tendência é crescer, principalmente com a obrigatoriedade de divulgação de balanços sociais por alguns setores mais regulados, como o setor de eletricidade, que já é obrigado a publicar a partir de 2003 (ANEEL, 2003). Além disso, a Comissão de Valores Mobiliários (CVM) tem proposto uma série de pontos sobre governança corporativa, incluindo a proposta de obrigatoriedade de divulgação do Balanço Social por empresas com faturamento anual superior a $\mathrm{R} \$ 150$ milhões e ativos de mais de R\$ 120 milhões, mesmo que não tenham capital aberto (BNDES, 2000). No campo ambiental, a nova Lei 10.650/2003 garante acesso público às informações existentes nos órgãos ambientais de todos os níveis de governo. Isto pode servir de balizamento para os stakeholders na hora de checar as informações apresentadas pelos balanços sociais.

Das informações dadas pelas empresas nos seus balanços sociais, fica explícito a relevância dos recursos das empresas que são direcionados para a sociedade, chegando a quase um terço das receitas operacionais líquidas das empresas que divulgaram valores para 2001 (vide Tabela 6). Os investimentos em ação social, a princípio voluntários, chegam a 3,6\% do lucro líquido das empresas que disponibilizaram resultados. Entretanto, não se pode confundir investimentos em projetos sociais, ou ação social, com responsabilidade social de empresas. RSE envolve muitas outras dimensões de conduta da empresa, como ética e legal.

Nesta pesquisa, e em outras que têm sido realizadas (SIQUEIRA \& VIDAL, 2002), existem problemas com a qualidade das informações contidas nos balanços sociais. Muitos balanços sociais não servem para fazer benchmarking para uma comparação entre empresas ou análise temporal. Detectou-se que alguns balanços apresentavam informações descritivas, sem consolidação e sem divisão temporal. Por exemplo, uma empresa colocou somente o total dos investimentos em ações sociais feitos ao longo dos anos, sem explicitar em que época foram feitos. Muitas simplesmente descreveram os projetos que apóiam sem analisar os resultados ou explicitar quantias. Também vemos que muitas empresas não publicam os balanços sociais anualmente e não têm datas exatas para divulgação. Os balanços saem com uma periodicidade esporádica, dificultando a comparação.

Outro lado da qualidade das informações refere-se à confiabilidade e às definições de alguns termos usados comumente em balanços sociais, como investimentos em ação/projetos sociais ou indicadores internos. Algumas empresas colocaram projetos externos de compromisso regulado (como projetos de eletrificação rural ou de compensação) como projetos sociais. Em uma empresa, seus investimentos sociais ultrapassavam seus investimentos totais. Finalmente, uma outra empresa do setor de saneamento colocava seus projetos de investimento na sua função fim (saneamento) como investimentos em meio ambiente. 
A qualidade das informações nos balanços sociais não é problema da realidade brasileira, e é recorrente em países que já tem uma maior tradição em balanços sociais, como os Estados Unidos e países da Europa (ADAMS, HILL \& ROBERTS, 1998; LESSEM, 1977). Um relatório do departamento de comércio dos Estados Unidos em 1979 já alertava para a falta de qualidade dos balanços sociais publicados na época (citado por HEARD \& BOLCE, 1981). Isto também acontece com algumas das maiores empresas do mundo (LINE, HAWLEY \& KRUT, 2002).

Organizações como o IBASE, CEBDS ou o Instituto Ethos tem desempenhado um papel importante na tentativa de melhorar a qualidade e formato de apresentação das informações contidas nos balanços sociais. O aprimoramento contínuo do Modelo IBASE de Balanço Social (já foram feitas algumas revisões ao longo dos anos) tem permitido a introdução de mais variáveis quantitativas e qualitativas. Espera-se que no futuro as comparações possam ser feitas com melhores parâmetros e informações mais confiáveis.

Uma empresa que não publica balanço não indica que seja menos socialmente responsável que outras que publicam. Muitos executivos pensam que responsabilidade social é cumprir a lei, e se a lei não pede não se deve publicar. Porém, o interesse do balanço social é divulgar informações para todos os stakeholders, e não somente para os fiscalizadores da lei, no caso o Estado. A publicação do BS mostra que a empresa está fazendo um esforço de pelo menos sistematizar e divulgar informações de caráter sócio-ambiental, que podem ser criticadas pela sociedade.

É notória a publicação de balanços sociais de empresas notadamente com problemas na área sócioambiental. Diversos autores defendem a publicação não só dos pontos e ações bons da organização, mas também a explic itação dos pontos ruins das empresas, ou uma autocrítica, (SIQUEIRA \& VIDAL, 2002; HINES, 1988;). Porém muitas vezes as empresas quando colocam pontos negativos tendem a fazê-los de uma forma mais defensiva, tentando explicá-los (SIQUEIRA \& VIDAL, 2002). Isto foi detectado em diversos balanços sociais analisados nesta pesquisa. Muitas vezes os balanços sociais podem refletir uma falsa realidade, mostrando aquilo que as empresas acham que iria agradar aos stakeholders. Seria usado como uma tentativa de legitimação frente aos stakeholders dando uma falsa realidade (HINES, 1988).

Alguns autores pensam que a obrigatoriedade e padronização dos balanços sociais acontecerão quando houver uma mudança na conscientização e poder dos stakeholders para que possam influenciar esta obrigatoriedade (ROBERTS, 1998). Além disso, é preciso que já estejam bem desenvolvidos requerimentos para atestar a qualidade das informações e formatos que possam servir para disseminar informações de forma confiável, o que não existe no momento. Porém, para isto, é necessário até mesmo termos um melhor amadurecimento do conceito de responsabilidade social corporativa.

Apesar de haver um esforço grande de muitas empresas em publicar seus Balanços Sociais, ainda não está claro se a maneira como as informações estão sendo apresentadas servem para o fim que o Balanço Social foi criado: ou seja, gerar um ambiente de transparência e confiança junto aos seus diversos stakeholders tornando públicas informações sócio-ambientais relevantes sobre a governança das empresas. Muitos balanços sociais na realidade parecem material de divulgação comercial da empresa, usando ações sócio-ambientais como uma estratégia de propaganda. Mais do que isso, o artigo indica que muitos balanços sociais, da forma como estão sendo publicados, podem ter um efeito contrário na credibilidade da empresa e ceticismo da idéia de responsabilidade social, e assim levar a uma perda de confiança dos stakeholders frente à empresa. Isto pode acontecer quando o balanço social é confuso e mal escrito e as informações são pouco confiáveis, irrelevantes, inconsistentes, incoerentes, pouco detalhadas e sem padronização. Um mau balanço pode indicar que a empresa tem 
problemas de gestão para busca de informações ou que está tentando fazer uma "maquiagem" sócioambiental. Quando a empresa tenta fazer do balanço social somente uma ferramenta de propaganda, na realidade pode estar tendo um efeito de propaganda negativa.

Com base nesta pesquisa, poderíamos recomendar ações pontuais para melhorar o papel do balanço social como ferramenta de construção da responsabilidade social de empresas, antes que esta ferramenta perca credibilidade devido a forma sem critérios como vem sendo publicada por muitas empresas. Isto incluiria ações como a padronização das informações divulgadas, inclusão das fontes dos dados, envolvimento de stakeholders na construção do BS, auditorias independentes e inserção da opinião dos stakeholders mais críticos. Porém, isto tudo deveria ser feito em um processo de discussão mais estruturado sobre balanços sociais, com a participação de especialistas e dos principais interessados na publicação dos balanços sociais, como empresas, representantes de contadores, governos, acadêmicos e outras organizações interessadas, como IBASE, Instituto Ethos, CVM, etc. O resultado seria a criação de uma série de diretrizes ou uma norma técnica voluntária para a publicação dos balanços, mas sem força de lei para que possa se mudar mais facilmente estas diretrizes com o tempo e circunstâncias à medida que a atividade de publicação de balanços sociais se torne mais madura.

Para finalizar, pensamos que há muito espaço para pesquisas futuras sobre balanço social. Elas devem se aprofundar não só de aperfeiçoamento do balanço social como uma ferramenta de gestão e sua regulamentação, mas tentar estudar a conexão do balanço social com temas maiores, por exemplo analisando o porquê de as empresas publicarem balanços sociais, como os stakeholders os tem utilizado e que impactos ele gera nas empresas e stakeholders.

\section{NOTAS}

${ }^{1}$ Cópia do modelo IBASE de balanço social pode ser encontrado na home-page do IBASE: www.ibase.br

${ }^{2}$ No contato telefônico, procuramos conversar diretamente com a pessoa responsável pelo balanço, quando possível. Caso houvesse algum tipo de informação, pedíamos que nos enviassem por e-mail ou correio.

${ }^{3}$ Setores que não conseguimos nenhum balanço social: Agropecuária; Aluguel de Veículos, Máquinas e Equipamentos; Atividades imobiliárias; Atividades recreativas, culturais e desportivas; Indústrias diversas; Máquinas e Equipamentos; Máquinas para escritório e Equipamentos de informática; Produtos alimentícios; Produtos de Madeira; Produtos de Metal; Saúde e serviços sociais; Serviços creditícios e conexos; Serviços de arquitetura e engenharia; Serviços de informática e conexos; Serviços prestados às empresas; Vigilância e segurança

${ }^{4}$ Algumas empresas no grupo das 95 selecionadas para análise não apresentavam resultados completos para alguns itens. Consideroutse estas empresas somente para comparações nos itens que elas apresentaram dados. 


\section{AGRADECIMENTOS}

Agredeço imensamente a equipe de pesquisa e ao apoio da EBAPE-FGV à pesquisa. Participaram da pesquisa Susana Arcangela Quacchia Feichas, José Jorge A. Abdalla, Elvira Cruvinel Ferreira Ventura, Margarida Maria de Fraga Rocha e Analice Araújo. Também contribuíram de forma fundamental para a coleta de dados as estagiárias Ana Luiza de Abreu Esteves, Karina Pereira de Carvalho, Samantha Mattos Pereira e Ludmilla da Silva Viana. Porém, os resultados aqui apresentados são de inteira responsabilidade do autor, e não representam a visão da EBAPE, da FGV ou de qualquer dos pesquisadores que participaram. Uma versão reduzida deste trabalho foi apresentada no XXVII Enanpad (Atibaia-SP, 2003).

\section{BIBLIOGRAFIA}

ADAMS, C. A.; HILL, W. \& ROBERTS, C. B. Corporate social reporting practices in Western Europe; legitimating corporate behavior? The British Accounting Review, vol. 30, n. 1, 1998, p. 1-21.

ANDRADE, José Célio Silveira; MARINHO, Márcia Mara de Oliveira; CARDOSO, Lígia F. \& SALATIEL Mariene. Relatório sócio-ambiental corporativo e produção sustentável Anais do XXXVII Congresso Latino-americano de Escolas de Administração (Cladea), Porto Alegre, 22 a 25 de outubro de 2002.

ANEEL - Agência Nacional de Eletricidade. Resolução 444. Disponível em: <www.aneel.gov.br>. Acesso em: 12 jan. 2003.

BNDES - Banco Nacional de Desenvolvimento Econômico e Social. Balanço Social e Outros Aspectos da Responsabilidade Social Corporativa. Relatório Setorial 2, AS/GESET, 2000, março (disponível em www.bndes.gov.br).

CEBDS - Conselho Empresarial Brasileiro para o Desenvolvimento Sustentável. Relatório de Sustentabilidade Empresarial - 2002. Rio de Janeiro: CEBDS, 2002.

DIERKES, Meinolf \& ANTAL, Ariane Berthoin. The usefulness and use of social reporting information. Accounting, Organizations and Society, vol . 10, n. 1, p. 29-34.

ETHOS, INSTITUTO. Guia de Elaboração do Balanço Social - 2002. Disponível em: <www.ethos.org.br>. Acesso em: 22 mar. 2003.

FGV - Fundação Getulio Vargas. As 500 maiores empresas S.A. não-financeiras. Revista Conjuntura Econômica, v. 56, n. 8, ago. 2002.

FREIRE, F. S. \& REBOUÇAS, T. R. S. Uma Descrição Sucinta do Balanço Social Francês, Português, Belga e Brasileiro. In: SILVA, César A. T. \& FREIRE, Fátima S. (Orgs.), Balanço Social: Teoria e Prática. São Paulo: Editora Atlas, 2001. 
GRI - Global Reporting Initiative. Sustainability Reporting Guidelines on Economic, Environmental and Social Performance, Global Reporting Initiative. Disponível em: <www.gri.org>. Acesso em: 24 jan. de 2003.

HEARD, J. E.; BOLCE, W. J. The political significance of corporate social reporting in the United States of America. Accounting, Organizations and Society, vol. 6, n. 3, p. 247-254, 1981.

HINES, R. D. Financial Accounting: In Communicating Reality, We Construct Reality. Accounting, Organizations and Society, vol. 13, n. 3, p. 251-261, 1988.

IBASE - Instituto Brasileiro de Análises Sociais e Econômicas. Transformando a frieza dos números em responsabilidade social. Disponível em: 〈www.ibase.br〉. Acesso em: 4 abr. 2003.

LESSEM, R. Corporate social reporting in action: An evaluation of British, European and American practice. Accounting, Organizations and Society, vol. 2, n. 4, p. 279-294, 1977.

LEWIS, L.; UNERMAN, J. ETHICAL RELATIVISM: A REASON FOR DIFFERENCES IN CORPORATE SOCIAL REPORTING?, Critical Perspectives on Accounting, vol. 10, n. 4, p. 521-547, 1999.

LINE, M; HAWLEY, H.; KRUT, R. The development of Global Environmental and Social Reporting. Corporate Environmental Strategies, v. 9, n. 1, p. 69-78, 2002.

LINE, M.; HAWLEY, H.; KRUT, R. The 2001 Benchmark Survey of the State of Global Environmental and Social Reporting. Disponível em: <www.csrnetwork.com〉. Acesso em: 28 set. 2002.

MAIGNAN, I.; FERREL, O.C.; HULT, G. Tomas M. Corporate citizenship: Cultural antecedents and business benefits. Academy of Marketing Science Journal, vol. 27, n. 4, p. 144-162, 1999.

MARTIN, R. The Virtue Matrix. Harvard Business Review, v. 80, n. 3, p. 66-77, 2002.

McWILLIANS, A.; SIEGEL, D. Corporate social responsibility and financial performance: correlation or misspecification? Strategic Management Journal, v. 21, n. 5, p. 28-39, 2000.

PRESTON, L E. Research on corporate social reporting: Directions for development. Accounting, Organizations and Society, vol. 6, n. 3, p. 255-262, 1981.

PUPPIM DE OLIVEIRA, J. A. Entendendo as respostas empresariais aos desafios sócio-ambientais no Brasil: Dois estudos de caso. Revista Portuguesa e Brasileira de Gestão, vol. 1, n. 1, p. 56-70, 2002.

PUPPIM DE OLIVEIRA, J. A. Um Balanço do Balanços Sociais. Harvard Business Review América Latina, p. 46-49, dez 2004,.

RAHAMAN, A S.; LAWRENCE, S.; ROPER, J. Social and environmental reporting at the VRA: institutionalised legitimacy or legitimation crisis? Critical Perspectives on Accounting, vol. 15; n. 1, p. 35-56, 2004.

ROBERTS, R. W. A stakeholder approach to the Corporate Single Audit. Critical Perspectives on Accounting, vol. 9, n. 2, p. 227-232, 1998. 
SHAOUL, J. Critical financial analysis and accounting for stakeholders. Critical Perspectives on Accounting, vol. 9, n. 2, p. 235-249, 1998.

SIQUEIRA, J. R. M.; VIDAL, M. C. R. Mensuração do impacto social das empresas: Uma abordagem qualitativa aos balanços sociais brasileiros. Anais do XXXVII Congresso Latino-americano de Escolas de Administração (Cladea), Porto Alegre, 22 a 25 de outubro de 2002.

SUTTON, S. G. \& ARNOLD, V.. Towards a framework for Corporate Single Audit: Meeting financial statement users' needs. Critical Perspectives on Accounting, vol. 9, n. 2, p. 177-191, 1998.

TEOH, Hai-Yap \& THONG, Gregory. Another look at corporate social responsibility and reporting: An empirical study in a developing country. Accounting, Organizations and Society, vol. 9, n. 2, p. 189-206, 1984.

\title{
Artigo recebido em 10.09.2003. Aprovado em 06.04.2004.
}

\author{
José Antônio Puppim de Oliveira \\ Professor Adjunto FGV-EBAPE \\ Interesses de pesquisa nas áreas de políticas de sustentabilidade e responsabilidade social de empresas e \\ debates sobre desenvolvimento sustentável. \\ E-mail: puppim@fgv.br \\ Endereço: Praia de Botafogo 190, sala 507, Rio de Janeiro - RJ, 22250-900.
}

